\title{
Remifentanil versus fentanyl during cardiac surgery on the incidence of chronic thoracic pain (REFLECT): study protocol for a randomized controlled trial
}

Sjoerd de Hoogd ${ }^{1}$, Sabine JGM Ahlers ${ }^{1}$, Eric PA van Dongen ${ }^{2}$, Dick Tibboel ${ }^{3}$, Albert Dahan ${ }^{4}$ and Catherijne AJ Knibbe ${ }^{1,3,5^{*}}$

\begin{abstract}
Background: Chronic thoracic pain after cardiac surgery is prevalent (11 to 56\%) and may affect patients' physical and mental health status. Despite its favorable pharmacokinetic and pharmacodynamic properties, high doses of remifentanil administered during surgery are reported to cause acute postoperative pain and increased requirements for analgesics. Recently, an association between remifentanil use and the incidence of chronic thoracic pain in the long term was also reported. Our objective is to investigate the influence of the intraoperative remifentanil on chronic postoperative pain in a prospective randomized controlled trial.

Methods/design: In this prospective, randomized, single-blind clinical trial, all patients ( $N=126)$ between 18 and 85 years undergoing cardiac surgery via sternotomy receive a continuous infusion of propofol together with intermittent intravenous fentanyl at predetermined times perioperatively. Patients are randomized to receive either an additional continuous infusion of remifentanil $\left(0.15 \mathrm{\mu g}^{-1} \mathrm{kglBW}^{-1} \mathrm{~min}^{-1}\right.$ ) or additional fentanyl (200 to $500 \mu \mathrm{g}$ ) as needed during surgery.

The primary end point is the prevalence of chronic thoracic pain 12 months after surgery. Secondary end points include acute postoperative pain; postoperative analgesic use; chronic thoracic pain 3 and 6 months after surgery; quality of life (SF-12) at 3, 6 and 12 months after surgery; work productivity; and use of health care. In addition, thermal detection and pain thresholds are measured preoperatively, 3 days after surgery and 12 months after surgery using quantitative sensory testing (QST). Finally, the influence of several genetic variances on the different outcomes will be measured.
\end{abstract}

Discussion: Chronic thoracic pain is prevalent after cardiac surgery, and research is needed to minimize the risk of chronic persistent postoperative pain, which is an invalidating, long-term complication of surgery. The objective of this trial is to determine the influence of perioperative remifentanil on long-term pain outcomes for cardiac patients in a prospective randomized trial. The results may be used to optimize perioperative analgesia techniques and, thereby, improve quality of life after cardiac surgery.

Trial registration: Clinicaltrials.gov NCT02031016 on 13 December 2013.

Keywords: Chronic pain, Sternotomy, Remifentanil, Fentanyl, Postoperative pain

\footnotetext{
*Correspondence: c.knibbe@antoniusziekenhuis.nl

'Department of Clinical Pharmacy, St Antonius Hospital, Koekoeklaan 1, 3435

CM Nieuwegein, The Netherlands

${ }^{3}$ Intensive Care and Department of Pediatric surgery, Erasmus MC - Sophia

Children's Hospital, Wytemaweg 80, 3015 CN Rotterdam, The Netherlands

Full list of author information is available at the end of the article
}

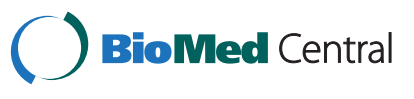

(c) 2014 de Hoogd et al.; licensee BioMed Central Ltd. This is an Open Access article distributed under the terms of the Creative Commons Attribution License (http://creativecommons.org/licenses/by/4.0), which permits unrestricted use, distribution, and reproduction in any medium, provided the original work is properly credited. The Creative Commons Public Domain Dedication waiver (http://creativecommons.org/publicdomain/zero/1.0/) applies to the data made available in this article, unless otherwise stated. 


\section{Background}

Remifentanil is a pain-relieving drug frequently used during surgery due to its favorable pharmacokinetic and pharmacodynamic properties. It is characterized by rapid onset, predictable rapid recovery profile and dosing reliability [1]. Its use is associated with a shorter length of hospital stay and duration of mechanical ventilation after cardiac surgery and a cardioprotective effect in coronary artery bypass graft (CABG) surgery patients [2,3]. On the other hand, high doses of remifentanil administered during surgery have been reported to cause acute postoperative pain and opioid-induced hyperalgesia [4]. Acute postoperative pain, in turn, is a major risk factor for the development of chronic pain [5-7]. Studies report incidences of chronic thoracic pain after cardiac surgery via sternotomy varying from $11 \%$ to $56 \%$, depending on the definition and the study population [8-12]. These patients reported significantly lower physical and mental health status compared to patients without chronic thoracic pain $[8,11,13,14]$.

Little is known about a possible association between the intraoperative use of remifentanil and the development of chronic pain. A dose-dependent relationship was shown in 90 cardiac patients one year after surgery [15]. Also a randomized study designed to evaluate allodynia after thoracotomy and the occurrence of chronic thoracic pain suggested that there might be an association between the use of high dose remifentanil and increased prevalence of chronic thoracic pain [16]. More recently, a retrospective study found that the combination of remifentanil and sevoflurane was less favorable in terms of chronic pain compared to a propofol and remifentanil combination. Patients with chronic pain had received a significantly higher dose of remifentanil, but significance was not reached in multivariate analysis [17].

In our hospital, about $60 \%$ of cardiac surgery patients receive remifentanil next to fentanyl intraoperatively, depending on the anesthetist's preference [15]. We wonder whether the possible development of hyperalgesia and chronic thoracic pain, with the negative impact on quality of life and cost efficacy, carries the risk of overcoming the advantages of remifentanil.

So far, however, no prospective randomized controlled trials designed to evaluate the influence of intraoperative remifentanil on the incidence of chronic thoracic pain are available. The current prospective randomized trial is designed to investigate the influence of perioperative additional remifentanil or additional fentanyl on the development of chronic thoracic pain at 3, 6 and 12 months after surgery. In addition, changes in thermal detection thresholds and pain thresholds and the influence of genetic variances will be investigated.

\section{Methods/design \\ Study design}

This study is a prospective, randomized, single-blind clinical trial carried out in the St. Antonius Hospital, Nieuwegein, the Netherlands (Figure 1). The study population consists of adult cardiac patients undergoing elective coronary artery bypass (CABG) surgery and/or valve replacement surgery via sternotomy. Patients are blinded for treatment and are randomly assigned to the remifentanil or fentanyl group.

The study was approved by the local Ethics Committee of this hospital (Verenigde Commissies Mensgebonden Onderzoek (VCMO) R13.013). The study was registered on the Clinical Trials register on 13 December 2013 (ClinicalTrials.gov number NCT02031016). The research coordinator will obtain written informed consent from each participant.

\section{Eligibility}

The following inclusion criteria are being applied: (1) patients undergoing cardiac surgery via sternotomy (a CABG and/or valve replacement); and (2) age between 18 and 85 years; (3) weight between 45 and $140 \mathrm{~kg}$. Exclusion criteria are: (1) pregnancy or breastfeeding; (2) language barrier; (3) history of drug abuse; (4) neurologic condition such as peripheral neuropathy and fibromyalgia; (5) known remifentanil, fentanyl, morphine or paracetamol allergy; (6) a body mass index (BMI) above $35 \mathrm{~kg} / \mathrm{m}^{2}$ (7) prior cardiac surgery (re-operations); and (8) patients with chronic pain conditions.

\section{Interventions}

\section{Intraoperative analgesic protocol}

Anesthesia will be induced with midazolam (2.5 to $5.0 \mathrm{mg}$ ) followed by a propofol bolus (1 to $2 \mathrm{mg} / \mathrm{kg}$ ), fentanyl (250 to $500 \mathrm{ug}$ ) and pancuronium $(0.05-2 \mathrm{mg} / \mathrm{kg})$. After tracheal intubation, patients will be ventilated to normocapnia with oxygen enriched air (50 to $100 \%$ oxygen). No nitrous oxide will be used. Sevoflurane will be used as needed. Both groups receive a continuous infusion of propofol (starting dose 200 to $300 \mathrm{mg} /$ hour) and intermittent intravenous fentanyl at predetermined times (that is, before incision, at sternotomy, at aorta cannulation and at opening of the pericardium).

Patients in the remifentanil group will receive a continuous infusion of remifentanil (starting infusion dose $0.15 \mathrm{ug} / \mathrm{kg}$ ideal body weight (IBW)/min) on top of this propofol-fentanyl anesthetic regimen. Patients in the fentanyl group will receive additional boluses of fentanyl 200 to $500 \mu \mathrm{g}$ as needed instead of the remifentanil infusion.

Patients in both groups will receive 5 to $10 \mathrm{mg}$ of intravenous morphine 30 minutes before the anticipated end of surgery. After surgery, patients will either go to 


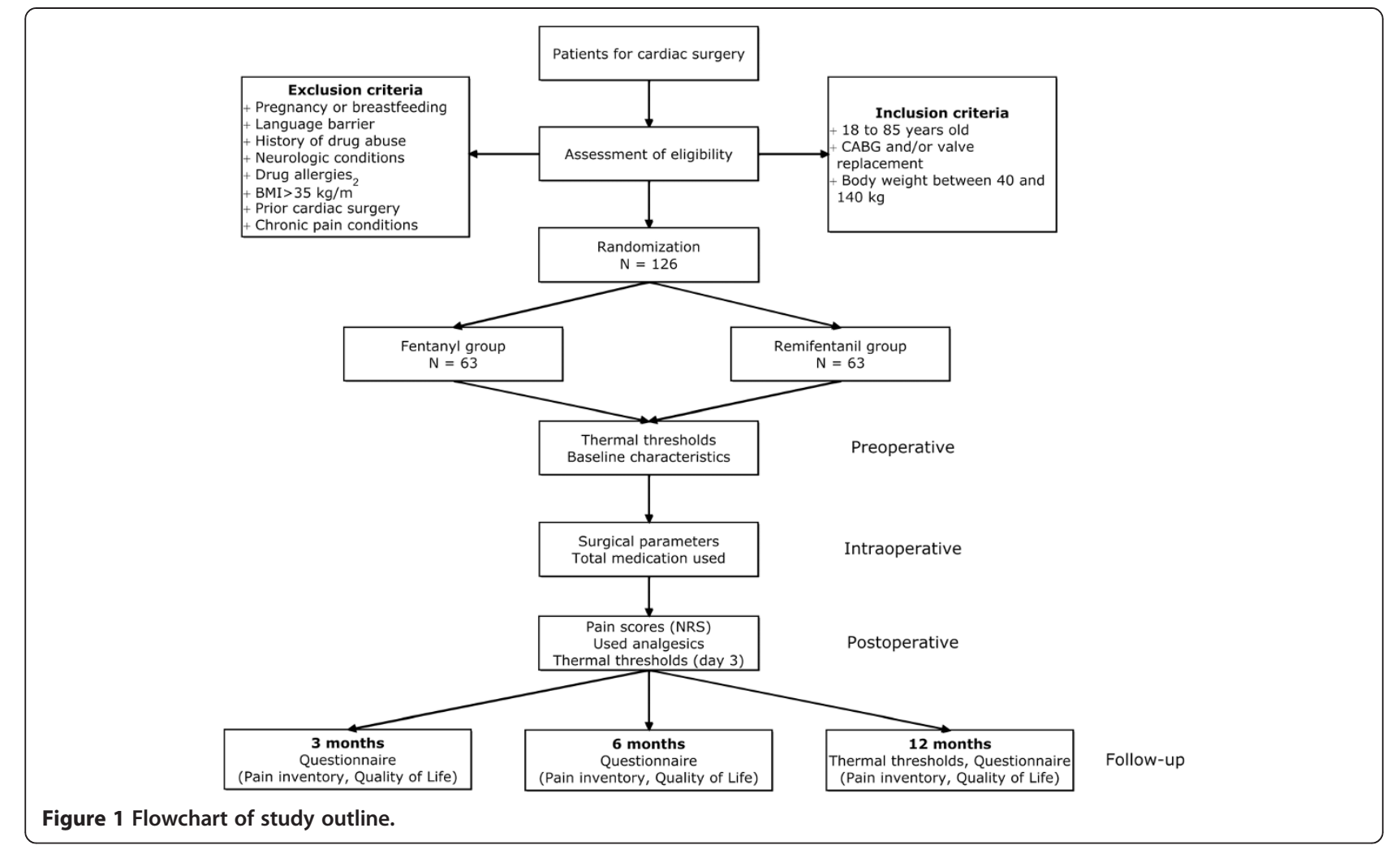

the Intensive Care Unit (ICU) or to the Post-Anesthesia Care Unit (PACU).

\section{Quantitative sensory testing}

One day before surgery, three days after surgery and one year after surgery quantitative sensory testing (QST) will be performed. Cold and warm detection thresholds and pain thresholds will be measured, using the 'method of limits' with the Thermal Sensory Analyzer (TSA) II 2001 (Medoc Advanced Medical Systems, U.S.) [18,19]. The threshold values will be corrected for age, gender and reaction time. Before the first test session, patients will be asked to practice testing at least twice. A test-retest variability of less than $20 \%$ is required before formal pain testing begins. The TSA II has been used extensively to determine warm/cold detection limits and warm/cold pain thresholds.

\section{Postoperative treatment}

Patients in both groups will receive the same postoperative treatment. In both the ICU and the PACU, a pain management protocol is in place as part of standard care, consisting of a continuous infusion of morphine (starting dose of $2 \mathrm{mg} /$ hour), which is adapted depending on Numerical Rating Scale (NRS) pain scores, as well as paracetamol four times a day (1 $\mathrm{g}$ oral/intravenous) [20]. Any perioperative fentanyl or remifentanil is discontinued at arrival at the ICU or PACU. NRS scores are assessed three times a day and administered medication is registered as part of standard care. On the general postoperative wards, the pain protocol consists of 2.5 to $10 \mathrm{mg}$ morphine (oral/intravenous) on demand and paracetamol four times a day ( $1 \mathrm{~g}$ oral).

\section{Follow-up}

After discharge from the hospital, patients will be asked to complete questionnaires 3, 6 and 12 months after surgery. This questionnaire contains questions about pain (perception, location, intensity) based on the Brief Pain Inventory [21] and was described previously [5]. In addition, quality of life (QoL) is measured with the short form (SF)-12 health status instrument, and work productivity and use of health care resources are measured. One year after cardiac surgery, pain thresholds are measured, using the same QST protocol.

\section{Primary end point and secondary end points}

The primary end point is the percentage of patients with chronic thoracic pain (NRS $>0$ ) one year after cardiac surgery.

Secondary end points are mean daily acute postoperative NRS scores (0 to 10) and analgesic consumption until discharge from the hospital. Also chronic pain (NRS), Quality of Life, analgesic consumption, work productivity, and use of health care 3, 6 and 12 months after surgery are assessed. In addition, warm/cold detection and pain 
thresholds (absolute and relative to preoperative values (baseline)) using quantitative sensory testing (QST) are considered. The length of ICU, PACU and hospital stay will be calculated.

In addition to primary and secondary endpoints, an exploratory screening of different genes in this population will be investigated. The possible influence of different genetic variances that are involved in pain sensitivity (for example, GTP-cyclohydrolase 1 (GCH-1), WDFY family member 4 (WDFY4), Zinc Finger gene Family (ZNF), Melanocortin 1 Receptor (MC1R)) and the pharmacokinetics and pharmacodynamics of opiates (for example, glucuronosyl transferase (UGT), Multidrug Resistance-associated Protein (MRP), mu-opioid receptor gene 1 (OPRM1), Catechol-O-methyltransferase (COMT)) will be explored.

\section{Data analysis}

Statistical analyses will be done with The SPSS statistical package (version 22.0 for Windows; SPSS, Chicago, IL). Patient demographics, baseline characteristics and clinical observations are compared between patients receiving remifentanil versus fentanyl during cardiac surgery. Nonparametric data will be expressed as median (range) and analyzed by chi-square. Parametric data will be expressed as mean \pm SD and analyzed by Student's t-tests or ranks tests.

The effect of intraoperative use of remifentanil on chronic pain one year after cardiac surgery is analyzed using univariate logistic regression analysis. If baseline characteristics are not balanced, multivariable techniques will be applied. To evaluate the effect of remifentanil versus fentanyl during cardiac surgery on pain thresholds, paired $t$-tests will be used.

To estimate the effect of the genotype on the outcome variables, each gene is examined to determine the appropriate model. The gene variants will be coded based on the observed distribution. The outcome parameters are compared between genotypes by a linear mixed model analysis based on the maximum likelihood ratio with the patient genotype status as fixed factors and the time point of outcome parameters as repeated measurement.

\section{Sample size calculations}

In a previous study of 90 patients on chronic thoracic pain after cardiac surgery, 15 of the 52 patients who received remifentanil developed chronic thoracic pain (29\%) versus 3 of the 38 patients who did not receive remifentanil (8\%); resulting in an odds ratio of 4.7 [15].

Rounding numbers, the sample size calculation is made on the assumption that in this prospective study, approximately $30 \%$ of the patients receiving remifentanil will develop chronic thoracic pain and that approximately $10 \%$ of the patients receiving fentanyl will develop chronic thoracic pain.
The sample size is calculated with a power of 0.80 and an alpha of 0.05 ; two sided. A total number of $117 \mathrm{pa}-$ tients are needed. According to previous reports, mortality thirty days after cardiac surgery is approximately 2 to $13.3 \%$ [22,23]. In a previous study, $8.4 \%$ died within one year after surgery [15]. Therefore, the total number of patients needed in this trial is $117 * 1.08=126$; 63 patients in each arm.

\section{Discussion}

This is the first randomized trial that prospectively evaluates the influence of intraoperative remifentanil on the incidence of chronic thoracic pain. Studies in healthy volunteers indicate that remifentanil increases the occurrence of secondary hyperalgesia in experimental pain models [24-28]. Other studies have described higher pain levels or analgesic requirements in the acute phase after surgery upon intraoperative use of remifentanil $[4,29,30]$. The clinical long-term relevance of these mostly short-term increases in pain scores, analgesic requirements or secondary hyperalgesia is unknown.

The putative biological mechanism by which remifentanil would cause chronic pain is unclear. Opioidinduced hyperalgesia is well described in animal studies but the occurrence in patients is still under debate [31]. Animal studies suggest that remifentanil influences the $\mathrm{N}$-methyl-D-aspartate (NDMA) currents by affecting opioid receptors [32,33]. Modulation of these NDMA currents could lead to central sensitization and consequently possibly to chronic postoperative pain.

Ideally, the study design should be double blind and contain no other opioid besides remifentanil. As a study arm without opioids during surgery is obviously unethical, fentanyl was selected for the other arm. The current design, where intermittent fentanyl at predetermined times is combined with continuous propofol as the basis for standardized Total Intravenous Anesthesia (TIVA) in both arms, is based on the design of a previous study investigating risk factors for chronic thoracic pain in our hospital [15]. With one arm randomized to an additional remifentanil infusion and one arm randomized to additional intermittent fentanyl as needed, these two study groups can both be considered the standard of care in our hospital. Given the familiarity with the two study arms, we do not expect unintentional effects from the nonblinding of anesthesiologists and ward nurses. It is emphasized that the patient is kept blinded for the treatment group, which is of particular relevance since it is the patient who determines the primary endpoint, that is, chronic thoracic pain one year after surgery. Another potential design that was considered was a group receiving remifentanil only with another group receiving fentanyl only. While the remifentanil-only group, in particular, cannot be considered a standard of care treatment in our 
hospital, we underline that when the current design was used in a previous nonrandomized study, a difference in the prevalence of chronic thoracic pain was detected [15].

In the current study, all patients will be evaluated for their sensory detection and pain thresholds using QST preoperatively, 3 days and 1 year after surgery. This randomized trial in which chronic thoracic pain after cardiac surgery is studied in the remifentanil and control arm is not only an opportunity to investigate the influence of remifentanil on sensory thresholds, but also to explore the influence of cardiac surgery and chronic pain on sensory modalities. Ideally, for this purpose, a pain battery with more than one stimulus (for example, electricity and pressure) should be used; however, in our opinion, use of a large number of pain thresholds measurements is not feasible in patients prior to and 3 days after invasive cardiac surgery.

The results of this randomized trial may be used to optimize intraoperative analgesia techniques and thereby improve the quality of life of patients after cardiac surgery.

\section{Trial status}

The trial is currently enrolling patients. To date, $90 \%$ of the patients have been enrolled in the study. The expected average enrollment rate is three to five patients every week. Data collection will stop one year after the last patient is included.

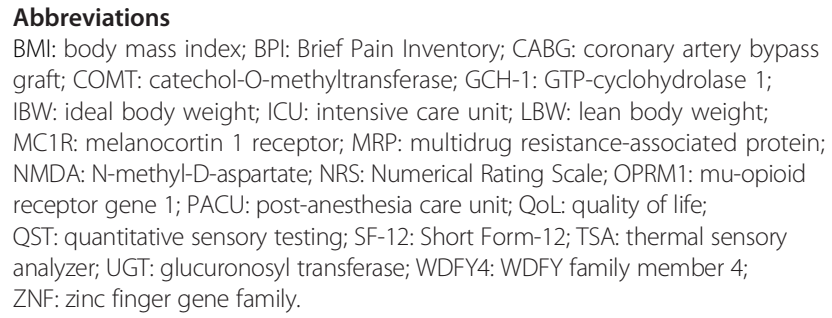

BMI: body mass index; BPI: Brief Pain Inventory; CABG: coronary artery bypass graft; COMT: catechol-O-methyltransferase; GCH-1: GTP-cyclohydrolase 1; IBW: ideal body weight; ICU: intensive care unit; LBW: lean body weight; MC1R: melanocortin 1 receptor; MRP: multidrug resistance-associated protein; NMDA: N-methyl-D-aspartate; NRS: Numerical Rating Scale; OPRM1: mu-opioid receptor gene 1; PACU: post-anesthesia care unit; QoL: quality of life; QST: quantitative sensory testing; SF-12: Short Form-12; TSA: thermal sensory analyzer; UGT: glucuronosyl transferase; WDFY4: WDFY family member 4; ZNF: zinc finger gene family.

\section{Competing interests}

The authors declare that they have no competing interests.

\section{Authors' contributions}

$\mathrm{SH}, \mathrm{SA}, \mathrm{ED}, \mathrm{DT}, \mathrm{AD}, \mathrm{CK}$ designed the study protocol; $\mathrm{SH}, \mathrm{SA}, \mathrm{CK}, \mathrm{ED}$ wrote the clinical protocol and obtained authorization from the Ethics Committee and wrote the manuscript. All authors read and approved the final manuscript.

\section{Acknowledgements \\ No financial support has been received for this study. \\ The authors thank Ko Hagoort for reviewing the manuscript.}

\footnotetext{
Author details

'Department of Clinical Pharmacy, St Antonius Hospital, Koekoeklaan 1, 3435 CM Nieuwegein, The Netherlands. ${ }^{2}$ Department of Anesthesiology and Intensive Care, St Antonius Hospital, Koekoeklaan 1, 3435 CM Nieuwegein, The Netherlands. ${ }^{3}$ Intensive Care and Department of Pediatric surgery, Erasmus MC - Sophia Children's Hospital, Wytemaweg 80, 3015 CN Rotterdam, The Netherlands. ${ }^{4}$ Department of Anesthesiology, Leiden University Medical Center, Albinusdreef 2, 2333 ZA, Leiden, The Netherlands. ${ }^{5}$ Division of Pharmacology, Leiden Academic Center for Drug Research, Leiden University, Einsteinweg 55, Leiden, The Netherlands.
}

Received: 8 August 2014 Accepted: 10 November 2014

Published: 27 November 2014

\section{References}

1. Derrode N, Lebrun F, Levron JC, Chauvin M, Debaene B: Influence of peroperative opioid on postoperative pain after major abdominal surgery: sufentanil $\mathrm{TCl}$ versus remifentanil $\mathrm{TCl}$. A randomized, controlled study. Br J Anaesth 2003, 91:842-849.

2. Wong GT, Huang $Z$, Ji S, Irwin MG: Remifentanil reduces the release of biochemical markers of myocardial damage after coronary artery bypass surgery: a randomized trial. J Cardiothorac Vasc Anesth 2010, 24:790-796.

3. Greco M, Landoni G, Biondi-Zoccai G, Cabrini L, Ruggeri L, Pasculli N, Giacchi V, Sayeg J, Greco T, Zangrillo A: Remifentanil in cardiac surgery: a meta-analysis of randomized controlled trials. J Cardiothorac Vasc Anesth 2012, 26:110-116.

4. Fletcher D, Martinez V: Opioid-induced hyperalgesia in patients after surgery: a systematic review and a meta-analysis. Br J Anaesth 2014, 112:991-1004.

5. van Gulik L, Janssen LI, Ahlers SJ, Bruins P, Driessen AH, van Boven WJ, van Dongen EP, Knibbe CA: Risk factors for chronic thoracic pain after cardiac surgery via sternotomy. Eur J Cardiothorac Surg 2011, 40:1309-1313.

6. Kehlet $\mathrm{H}$, Jensen TS, Woolf CJ: Persistent postsurgical pain: risk factors and prevention. Lancet 2006, 367:1618-1625.

7. Choiniere M, Watt-Watson J, Victor JC, Baskett RJ, Bussieres JS, Carrier M, Cogan J, Costello J, Feindel C, Guertin MC, Racine M, Taillefer MC: Prevalence of and risk factors for persistent postoperative nonanginal pain after cardiac surgery: a 2-year prospective multicentre study. CMAJ 2014, 186:E213-E223.

8. Eisenberg E, Pultorak Y, Pud D, Bar-El Y: Prevalence and characteristics of post coronary artery bypass graft surgery pain (PCP). Pain 2001, 92:11-17.

9. Kalso E, Mennander S, Tasmuth T, Nilsson E: Chronic post-sternotomy pain. Acta Anaesthesiol Scand 2001, 45:935-939.

10. Lahtinen $\mathrm{P}, \mathrm{Kokki} \mathrm{H}$, Hynynen M: Pain after cardiac surgery: a prospective cohort study of 1-year incidence and intensity. Anesthesiology 2006, 105:794-800.

11. Gjeilo KH, Klepstad P, Wahba A, Lydersen S, Stenseth R: Chronic pain after cardiac surgery: a prospective study. Acta Anaesthesiol Scand 2010, 54:70-78.

12. Meyerson J, Thelin S, Gordh T, Karlsten R: The incidence of chronic poststernotomy pain after cardiac surgery-a prospective study. Acta Anaesthesiol Scand 2001, 45:940-944.

13. Bruce J, Drury N, Poobalan AS, Jeffrey RR, Smith WC, Chambers WA: The prevalence of chronic chest and leg pain following cardiac surgery: a historical cohort study. Pain 2003, 104:265-273.

14. Taillefer MC, Carrier M, Belisle S, Levesque S, Lanctot H, Boisvert AM, Choiniere M: Prevalence, characteristics, and predictors of chronic nonanginal postoperative pain after a cardiac operation: a crosssectional study. J Thorac Cardiovasc Surg 2006, 131:1274-1280.

15. van Gulik L, Ahlers SJ, van de Garde EM, Bruins P, van Boven WJ, Tibboel D, van Dongen EP, Knibbe CA: Remifentanil during cardiac surgery is associated with chronic thoracic pain $1 \mathrm{yr}$ after sternotomy. $\mathrm{Br} J$ Anaesth 2012, 109:616-622.

16. Salengros JC, Huybrechts I, Ducart A, Faraoni D, Marsala C, Barvais L, Cappello M, Engelman E: Different anesthetic techniques associated with different incidences of chronic post-thoracotomy pain: low-dose remifentanil plus presurgical epidural analgesia is preferable to high-dose remifentanil with postsurgical epidural analgesia. J Cardiothorac Vasc Anesth 2010, 24:608-616.

17. Cho AR, Kwon JY, Kim KH, Lee HJ, Kim HK, Kim ES, Hong JM, Kim C: The effects of anesthetics on chronic pain after breast cancer surgery. Anesth Analg 2013, 116:685-693.

18. Rolke R, Baron R, Maier C, Tolle TR, Treede RD, Beyer A, Binder A, Birbaumer N, Birklein F, Botefur IC, Braune S, Flor H, Huge V, Klug R, Landwehrmeyer GB, Magerl W, Maihofner C, Rolko C, Schaub C, Scherens A, Sprenger T, Valet M, Wasserka B: Quantitative sensory testing in the German Research Network on Neuropathic Pain (DFNS): standardized protocol and reference values. Pain 2006, 123:231-243.

19. Rolke R, Magerl W, Campbell KA, Schalber C, Caspari S, Birklein F, Treede RD: Quantitative sensory testing: a comprehensive protocol for clinical trials. Eur J Pain 2006, 10:77-88.

20. Ahlers SJ, van Gulik L, van Dongen EP, Bruins P, van de Garde EM, van Boven WJ, Tibboel D, Knibbe CA: Efficacy of an intravenous bolus of 
morphine 2.5 versus morphine $7.5 \mathrm{mg}$ for procedural pain relief in postoperative cardiothoracic patients in the intensive care unit: a randomised double-blind controlled trial. Anaesth Intensive Care 2012, 40:417-426.

21. Cleeland CS, Ryan KM: Pain assessment: global use of the Brief Pain Inventory. Ann Acad Med Singapore 1994, 23:129-138.

22. Edwards FH, Peterson ED, Coombs LP, DeLong ER, Jamieson WR, Shroyer ALW, Grover FL: Prediction of operative mortality after valve replacement surgery. J Am Coll Cardiol 2001, 37:885-892.

23. Noordzii PG, Poldermans D, Schouten O, Bax JJ, Schreiner FA, Boersma E: Postoperative mortality in The Netherlands: a population-based analysis of surgery-specific risk in adults. Anesthesiology 2010, 112:1105-1115.

24. Angst MS, Koppert W, Pahl I, Clark DJ, Schmelz M: Short-term infusion of the mu-opioid agonist remifentanil in humans causes hyperalgesia during withdrawal. Pain 2003, 106:49-57.

25. Koppert W, Angst M, Alsheimer M, Sittl R, Albrecht S, Schuttler J, Schmelz M: Naloxone provokes similar pain facilitation as observed after short-term infusion of remifentanil in humans. Pain 2003, 106:91-99.

26. Koppert W, Sittl R, Scheuber K, Alsheimer M, Schmelz M, Schuttler J: Differential modulation of remifentanil-induced analgesia and postinfusion hyperalgesia by S-ketamine and clonidine in humans. Anesthesiology 2003, 99:152-159.

27. Lenz H, Raeder J, Draegni T, Heyerdahl F, Schmelz M, Stubhaug A: Effects of COX inhibition on experimental pain and hyperalgesia during and after remifentanil infusion in humans. Pain 2011, 152:1289-1297.

28. Troster A, Sittl R, Singler B, Schmelz M, Schuttler J, Koppert W: Modulation of remifentanil-induced analgesia and postinfusion hyperalgesia by parecoxib in humans. Anesthesiology 2006, 105:1016-1023.

29. Kim SH, Stoicea N, Soghomonyan S, Bergese SD: Intraoperative use of remifentanil and opioid induced hyperalgesia/acute opioid tolerance: systematic review. Front Pharmacol 2014, 5:108.

30. Rivosecchi RM, Rice MJ, Smithburger PL, Buckley MS, Coons JC, Kane-Gill SL: An evidence based systematic review of remifentanil associated opioid-induced hyperalgesia. Expert Opin Drug Saf 2014, 13:587-603.

31. Raffa RB, Pergolizzi JV Jr: Opioid-induced hyperalgesia: is it clinically relevant for the treatment of pain patients? Pain Manag Nurs 2013, 14:e67-e83.

32. Guntz E, Dumont H, Roussel C, Gall D, Dufrasne F, Cuvelier L, Blum D, Schiffmann SN, Sosnowski M: Effects of remifentanil on N-methyl-Daspartate receptor: an electrophysiologic study in rat spinal cord. Anesthesiology 2005, 102:1235-1241

33. Zhao M, Joo DT: Enhancement of spinal N-methyl-D-aspartate receptor function by remifentanil action at delta-opioid receptors as a mechanism for acute opioid-induced hyperalgesia or tolerance. Anesthesiology 2008, 109:308-317.

doi:10.1186/1745-6215-15-466

Cite this article as: de Hoogd et al:: Remifentanil versus fentanyl during cardiac surgery on the incidence of chronic thoracic pain (REFLECT): study protocol for a randomized controlled trial. Trials 2014 15:466.

\section{Submit your next manuscript to BioMed Central and take full advantage of:}

- Convenient online submission

- Thorough peer review

- No space constraints or color figure charges

- Immediate publication on acceptance

- Inclusion in PubMed, CAS, Scopus and Google Scholar

- Research which is freely available for redistribution 